\title{
Glucose Metabolism by Lactobacillus divergens
}

\author{
By INGRID N. DE BRUYN, ${ }^{1}$ WILHELM H. HOLZAPFEL ${ }^{1} \dagger$ \\ LEON VISSER ${ }^{2}$ AND ABRAHAM I. LOUW, ${ }^{2 *}$ \\ Departments of Microbiology ${ }^{1}$ and Biochemistry ${ }^{2}$, University of Pretoria, 0002 Pretoria, \\ Republic of South Africa
}

(Received 12 April 1988)

\begin{abstract}
Earlier studies on the fermentation of $\mathrm{D}-\left[1-{ }^{14} \mathrm{C}\right]-$ and $\mathrm{D}-\left[3,4-{ }^{14} \mathrm{C}\right]$ glucose by Lactobacillus divergens showed that lactate was the major fermentation product and that it was probably produced by glycolysis. It was therefore recommended that $L$. divergens be reclassified as a homofermentative organism. In the present investigation, products of $\mathrm{D}-\left[1-{ }^{14} \mathrm{C}\right]-, \mathrm{D}-\left[2-{ }^{14} \mathrm{C}\right]-$ and D- $\left[3,4-{ }^{14} \mathrm{C}\right] \mathrm{glucose}$ fermented by $L$. divergens were isolated, and their specific radioactivities and the distribution patterns of radioactivity in their $\mathrm{C}$-atoms were determined. The positional labelling patterns of the fermentation products, their specific radioactivities and their concentrations confirmed that glucose is degraded via the glycolytic pathway. Some secondary decarboxylation/dissimilation of pyruvate to acetate, formate and $\mathrm{CO}_{2}$ was also observed. These results provide conclusive proof that $L$. divergens is indeed a homofermentative organism. Results obtained with $\mathrm{D}-\left[\mathrm{U}-{ }^{14} \mathrm{C}\right]$ glucose showed that approximately three-quarters of the lactate but less than $10 \%$ each of the formate and acetate were produced from glucose. The remainder was presumably derived to a varying degree from endogenous non-glucose sources such as fructose and/or amino acids.
\end{abstract}

\section{INTRODUCTION}

Lactobacillus divergens, isolated from vacuum-packaged meat, was initially classified as an atypical heterofermentative organism (Holzapfel \& Gerber, 1983). Recent radioactivity incorporation studies with $\mathrm{D}-\left[1-^{14} \mathrm{C}\right]$-and $\mathrm{D}-\left[3,4^{-14} \mathrm{C}\right]$ glucose as substrates have, however, suggested that $L$. divergens metabolizes glucose principally by the glycolytic pathway (De Bruyn et al., 1987), and it was recommended that the organism be reclassified as a homofermentative organism.

These studies have now been extended to provide information on the distribution of the ${ }^{14} \mathrm{C}$ label in the fermentation products of $D-\left[1-{ }^{14} \mathrm{C}\right]-\mathrm{D}-\left[2-{ }^{14} \mathrm{C}\right]-$ and $\mathrm{D}-\left[3,4-{ }^{14} \mathrm{C}\right] \mathrm{glucose}$. The results allow definitive conclusions to be drawn on the principal route by which $L$. divergens metabolizes glucose.

\section{METHODS}

Strain and materials. Lactobacillus divergens, isolate 66 (DSM 20623), from our collection (Holzapfel \& Gerber, 1983) was used. D-[1-14 C]Glucose [specific activity $\left.53.4 \mathrm{mCi} \mathrm{mmol}^{-1}(1 \mathrm{mCi}=37 \mathrm{MBq})\right], \mathrm{D}-[2-14 \mathrm{C}] \mathrm{glucose}(49 \cdot 3$ $\left.\mathrm{mCi} \mathrm{mmol}{ }^{-1}\right)$ and $\mathrm{D}-\left[3,4-{ }^{14} \mathrm{C}\right] \mathrm{glucose}\left(10 \cdot 32 \mathrm{mCi} \mathrm{mmol}^{-1}\right)$ were obtained from New England Nuclear. D-[U${ }^{14} \mathrm{C}$ Glucose (specific activity $286 \mathrm{mCi} \mathrm{mmol}^{-1}$ ) was from ICN Radiochemicals. Insta-gel II was obtained from Packard Instrument Co. All reagents for HPLC were of HPLC-grade (Merck). Water was twice-distilled in glass and deionized in a Milli-Q water system (Millipore).

Radioactivity measurements. These were made with a Packard Tricarb model 4430 liquid scintillation counter with automatic external standardization. Samples were counted either to a confidence limit of $95.5 \%$ and an uncertainty of $1 \%$, or for $300 \mathrm{~min}$. Only radioactivity values higher than twice the background were used.

† Present address: Institut für Hygiene und Toxikologie der BFE, Engesserstr. 20, D-7500 Karlsruhe 1, FRG. 
Fermentation experiments. The fermentation of differently labelled glucose, and the extraction and isolation of fermentation products by HPLC, were done as described earlier (De Bruyn et al., 1987). L. divergens was pregrown in modified MRS broth at $\mathrm{pH} 8.5$ (containing sucrose instead of glucose and without acetate) for $14 \mathrm{~h}$ at $25^{\circ} \mathrm{C}$. The cells were harvested during the exponential growth phase by centrifugation, washed twice with $0.047 \mathrm{M}$ sodium/potassium phosphate buffer $\mathrm{pH} 7.8$, and suspended in $4 \mathrm{ml}$ of the same buffer. Fermentation was carried out in a Gilson respirometer by adding $1 \mathrm{ml}$ cell suspension to about $55 \mu \mathrm{mol}$ glucose in $2 \mathrm{ml} 0.047 \mathrm{M}$-phosphate buffer. Labelled glucose was added to the final specific radioactivities given in Table 1 . After $2.5 \mathrm{~h}$ at $25^{\circ} \mathrm{C}$, fermentation was terminated on ice and the filter paper plus $\mathrm{KOH}$ from the centre well of the Gilson flask was placed in a glass scintillation vial. Radiolabelled $\mathrm{CO}_{2}$, as $\mathrm{KH}^{14} \mathrm{CO}_{3}$, was determined by liquid scintillation counting after addition of $12 \mathrm{ml}$ Insta-gel II and standing for $15 \mathrm{~h}$ to allow for the decay of chemiluminescence. A separate flask containing $0.2 \mathrm{ml}$ water in the centre well instead of $2 \% \mathrm{KOH}$ was included to determine the amount of $\mathrm{CO}_{2}$ produced.

Recovery and analysis of fermentation products. The fermentation products were quantitatively recovered ( $\geq 98 \%$ ) by four successive extractions of the contents of the Gilson flasks according to Guerrant et al. (1982). The extracts were freeze-dried, dissolved in water and the fermentation products separated by HPLC using an Aminex HPX-87H cation-exchange column (Bio-Rad) with $10.8 \%(\mathrm{v} / \mathrm{v})$ acetonitrile in $0.0035 \mathrm{M}-\mathrm{H}_{2} \mathrm{SO}_{4}$ as eluent (Guerrant et al., 1982). The concentration of lactate was determined by enzymic assay according to Noll (1974). The concentrations of acetate and formate were determined from HPLC peak heights, unless indicated otherwise.

Endogenous end-product dilution, caused by the metabolism of other unknown substrates (Dawes, 1980), was ascertained from the specific activity of the end-products of fermentation of $10 \mu \mathrm{Ci} \mathrm{D}-\left[\mathrm{U}-{ }^{14} \mathrm{C}\right] \mathrm{glucose}$ by $L$. divergens using the method described above.

The specific radioactivity of glucose was determined after its extraction from a zero-time Gilson flask according to Williams et al. (1971). Glucose was purified from the extract by HPLC on a Radial-Pak Silica Cartridge with Radial Compression Module (Waters Associates) with $75 \%$ acetonitrile and $0.1 \%$ tetraethylene pentamine in water as eluant at a flowrate of $3 \mathrm{ml} \mathrm{min}{ }^{-1}$. The concentration of glucose was determined by enzymic assay (Bernt \& Bergmeyer, 1974) and its radioactivity by liquid scintillation counting.

The chemical degradation of the respective organic acids was essentially according to Williams et al. (1971) except that about $25 \mathrm{mg}$ unlabelled lactic acid or acetic acid was added to each of their respective radioactive counterparts (isolated by HPLC). $\mathrm{CO}_{2}$ resulting from the oxidation was trapped as $\mathrm{BaCO}_{3}$, the suspension was transferred to a clean and pre-weighed glass centrifuge tube, and the $\mathrm{BaCO}_{3}$ precipitate was recovered by centrifugation. The supernatant was carefully removed and discarded. The $\mathrm{BaCO}_{3}$ precipitate was washed three times with $5 \mathrm{ml}$ hot water to remove any remaining $\mathrm{Ba}(\mathrm{OH})_{2}$, dried at $100{ }^{\circ} \mathrm{C}$ for $36 \mathrm{~h}$, cooled to room temperature in a desiccator and weighed. A $20 \mathrm{mg}$ portion of the dried $\mathrm{BaCO}_{3}$ precipitate was transferred to a $20 \mathrm{ml}$ glass counting vial and $6 \mathrm{ml}$ water was added. The vials were placed in a Bransonic model 42 sonic bath for a few minutes until a homogeneous colloidal suspension was formed. Insta-gel II $(8 \mathrm{ml})$ was added and the mixture was vortexed. The radioactivity of the resulting gel suspension of $\mathrm{BaCO}_{3}$ was measured. A vial containing $6 \mathrm{ml}$ water and $8 \mathrm{ml}$ Insta-gel II was used as a blank. Counting efficiencies were determined by both external and internal standardization. Only $95 \%$ of the actual counts in $\mathrm{BaCO}_{3}$ was accounted for by the external standardization method. The remaining $5 \%$ was presumably lost by self-absorption, as was also reported by Cluley (1962). All results obtained for $\mathrm{BaCO}_{3}$ were corrected for this self-absorption.

\section{RESULTS AND DISCUSSION}

\section{Labelling patterns from differently labelled glucose precursors}

In Table 1 it is shown that lactate was the only major radioactive product produced from the differently labelled glucose precursors, confirming our previous findings (De Bruyn et al., 1987) and agreeing with the expected symmetric fermentation pathway of glycolysis (Fig. $1 a$ ). The low incorporation of radioactivity into $\mathrm{CO}_{2}$ produced from $\mathrm{D}-\left[1{ }^{-14} \mathrm{C}\right]$ glucose, or into acetate produced from $\mathrm{D}-\left[3,4-{ }^{14} \mathrm{C}\right] \mathrm{glucose}$, indicates that only a small amount of glucose was fermented by the hexose monophosphate (Fig. $1 b$ ) and/or Entner-Doudoroff (Fig. 1c) pathways.

\section{End-product dilution}

The specific radioactivity of lactate produced from $D-\left[1-{ }^{14} C\right]-, D-\left[2-{ }^{14} C\right]-$ and $D-[3,4-$ ${ }^{14} \mathrm{C}$ ]glucose came to only $38.6 \%, 38.7 \%$ and $38.0 \%$ of that of the respective glucose precursors (Table 1). The corresponding values for $\mathrm{CO}_{2}$, acetate and formate were even lower. If glycolysis is the major pathway of glucose fermentation and if glucose is the only fermentable substrate, the specific radioactivity of all of the end-products is expected to be half that of glucose (Fig. 1a). 


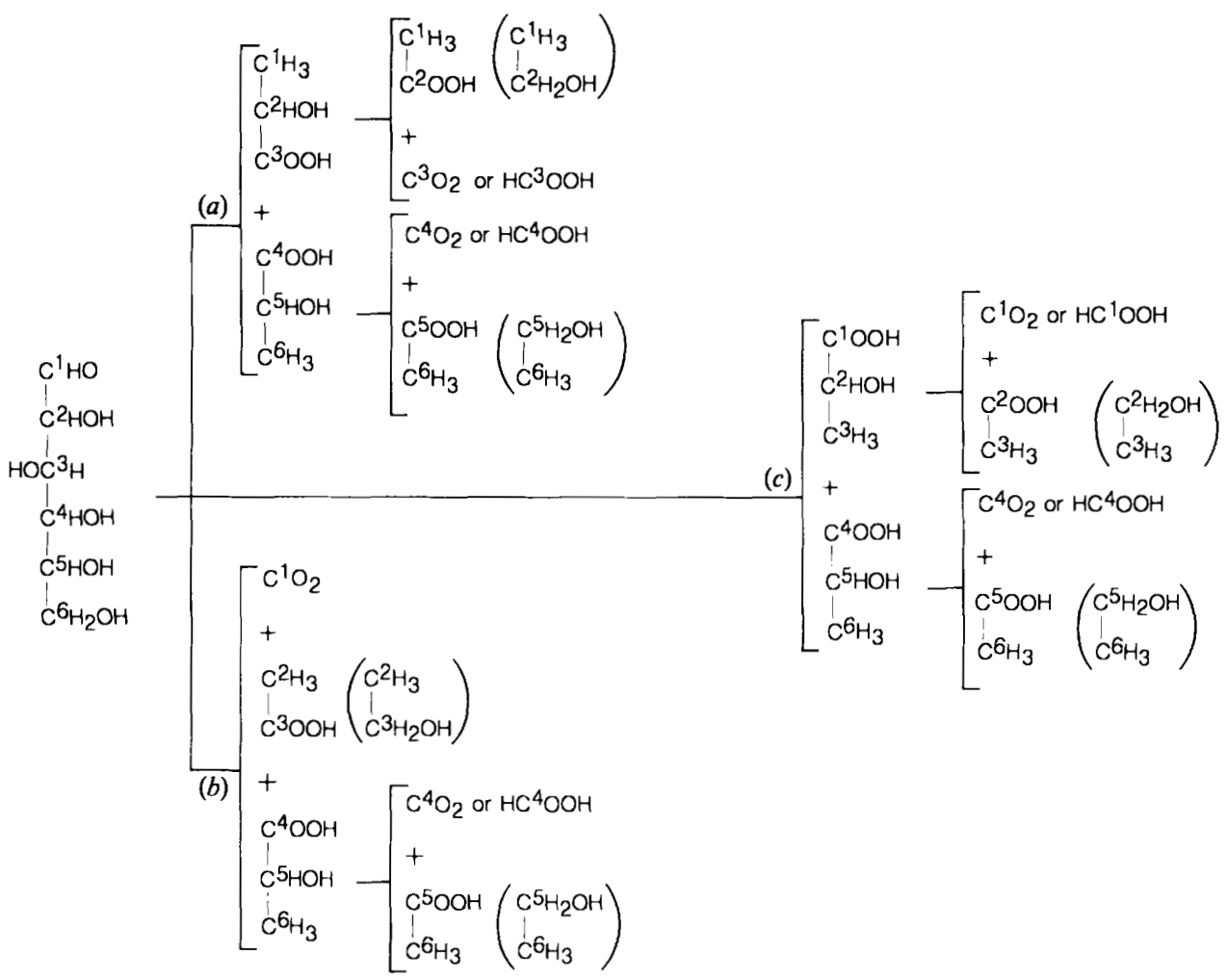

Fig. 1. Distribution of $\mathrm{C}$-atoms in products obtained from the fermentation of glucose by lactobacilli (Abo-Elnaga \& Kandler, 1965). (a) Glycolytic pathway, (b) hexose monophosphate pathway, (c) Entner-Doudoroff pathway.

Uniformly labelled $\mathrm{D}-\left[\mathrm{U}-{ }^{14} \mathrm{C}\right]$ glucose was therefore used as substrate in order to establish whether end-product dilution had occurred, and to what extent.

The results obtained with $\mathrm{D}-\left[\mathrm{U}-{ }^{14} \mathrm{C}\right]$ glucose (Table 2 ) show that only $76 \cdot 7 \%, 42 \cdot 8 \%, 8 \cdot 7 \%$ and $6.3 \%$, respectively, of the expected lactate, $\mathrm{CO}_{2}$, acetate and formate were produced from glucose under the experimental conditions employed. The remainder was derived to a varying degree from unknown endogenous sources. It is significant that unequal dilution of the fermentation products had occurred. About $23 \%$ of the lactate was derived from endogenous substrates other than radioactive glucose, whereas almost $60 \%$ of the $\mathrm{CO}_{2}$ and more than $90 \%$ of each of the acetate and formate came from other sources. If identical metabolic pathways were responsible for the production of lactate as well as that of $\mathrm{CO}_{2}$, acetate and formate, the extent of dilution would have been the same. The results clearly indicate that the latter two products were mainly formed by metabolic pathways other than those by which lactate was produced.

Although stock cultures of $L$. divergens were pre-grown in a medium containing sucrose (see Methods), it is unlikely that the remaining intracellular sucrose (or glucose and fructose derived from it) could have contributed significantly to the end-product dilution observed after D-[U${ }^{14} \mathrm{C}$ ]glucose fermentation by the washed cells. This is particularly so in view of the relatively high concentration (about $55 \mu \mathrm{mol}$ ) of labelled glucose in the medium. Some bacteria ferment amino acids to $\mathrm{NH}_{3}, \mathrm{CO}_{2}$, acetate, formate, butyrate and $\mathrm{H}_{2}$ by the Stickland reaction (Gottschalk, 1979; Stams et al., 1985). L. divergens was originally isolated from raw, minced meat (Holzapfel \& Gerber, 1983). It is conceivable that the organism could have produced these fermentation products from intracellular amino acids, accumulated during pre-growth in the peptone-containing medium (see Methods). 


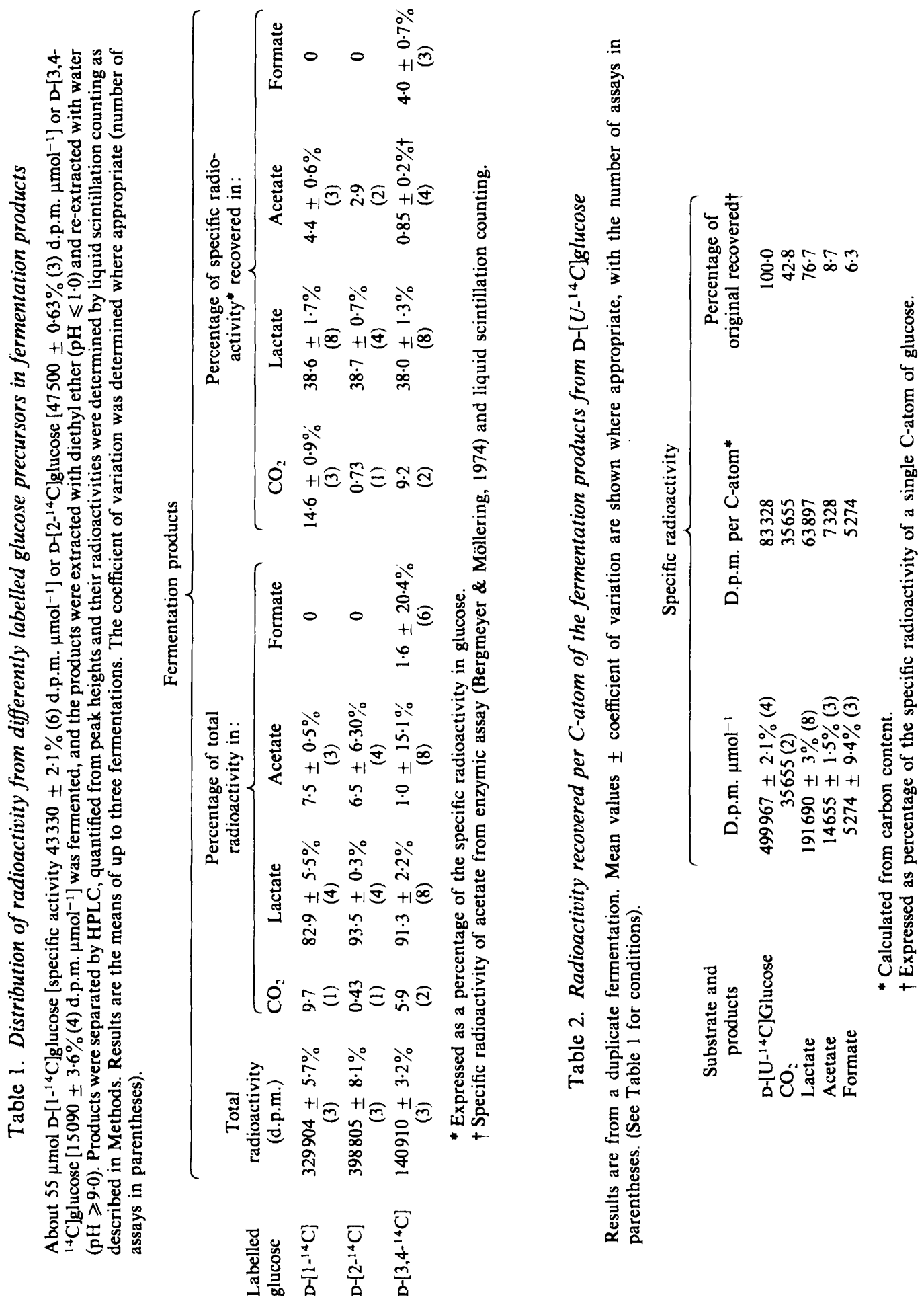



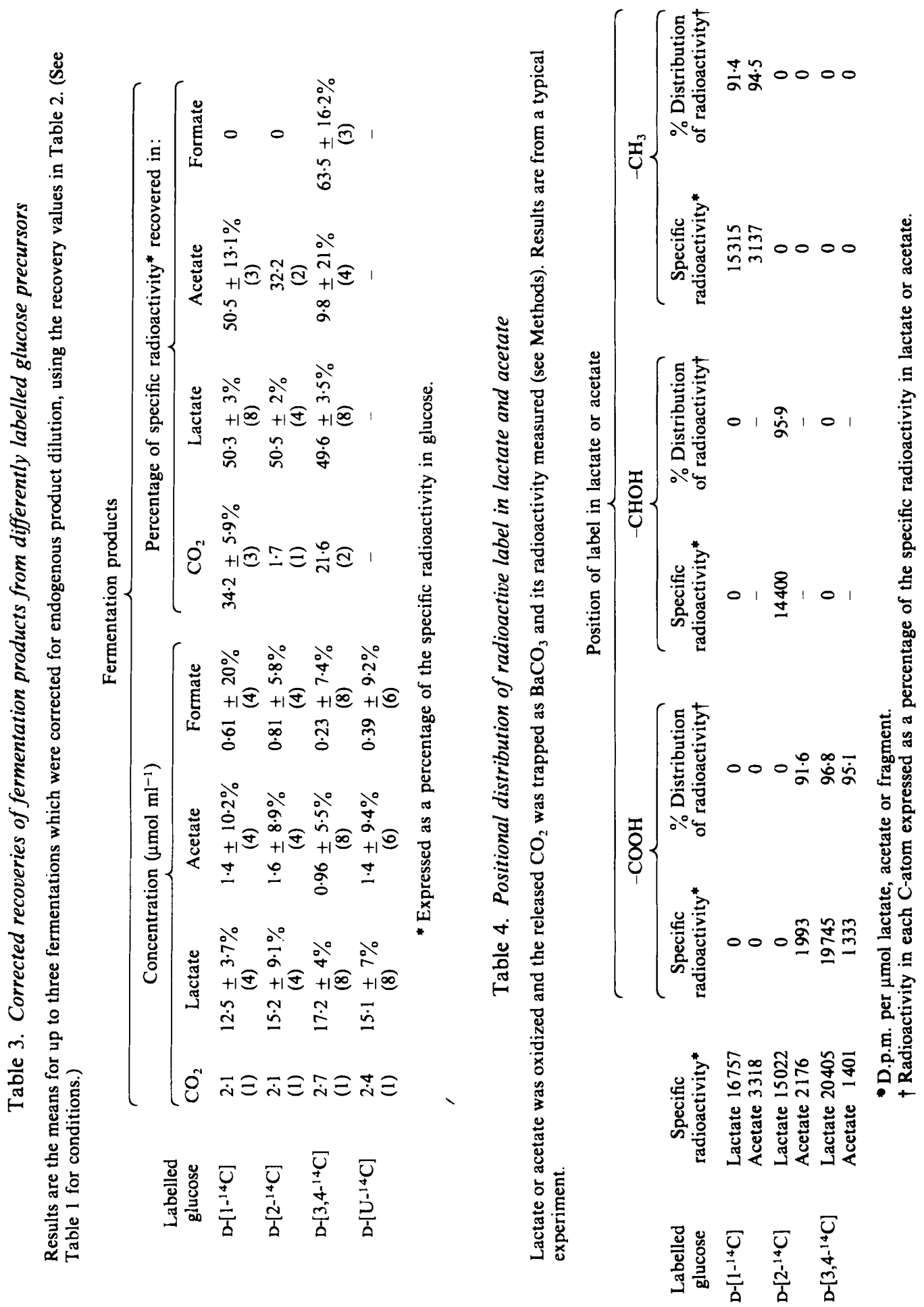


\section{Corrected recoveries of fermentation products derived from differently labelled glucose precursors}

The observed concentrations and specific radioactivities of each fermentation product were corrected for endogenous product dilution according to the results of Table 2. From the corrected concentrations (Table 3), it is again obvious that lactate was the major product of glucose metabolism by $L$. divergens. The corrected specific radioactivities of lactate, which came to $50 \cdot 3 \%, 50.5 \%$ and $49.6 \%$ of that of $\mathrm{D}-\left[1-{ }^{14} \mathrm{C}\right]-\mathrm{D}-\left[2-{ }^{14} \mathrm{C}\right]-$ or $\mathrm{D}-\left[3,4-{ }^{14} \mathrm{C}\right]$ glucose, respectively, are close to the expected value of $50 \%$ for glucose fermented to lactate via glycolysis.

It is also evident that in some cases the corrected specific radioactivities of $\mathrm{CO}_{2}$ and acetate came to less than $50 \%$ of that of the glucose precursors (Table 3). Substantial further dilution presumably had occurred by unlabelled end-products formed in the hexose monophosphate or Entner-Doudoroff pathways, and/or secondary transformations of pyruvate (Fig. 1 and De Bruyn et al., 1987). It was not possible to draw firm conclusions about the relative contributions of the latter pathways from the distribution and recovery of radioactivity in the fermentation products alone. A more definitive answer was therefore sought by analysis of the positional distribution of radioactivity in the individual $\mathrm{C}$-atoms of the fermentation products.

\section{Positional distribution of radioactivity in lactate and acetate}

Lactate produced from $\mathrm{D}-\left[3,4-{ }^{14} \mathrm{C}\right]$ glucose was exclusively labelled in its carboxyl carbon, while acetate produced from $D-\left[1-{ }^{14} \mathrm{C}\right]$ glucose was exclusively labelled in its methyl carbon (Table 4). These results are in agreement with those expected for fermentation products formed by glycolysis (Fig. 1 $a$ ). If the Entner-Doudoroff pathway (Fig. 1c) had been operative, the label in lactate produced from $D-\left[3,4-{ }^{14} \mathrm{C}\right]$ glucose would have been distributed equally between the carbons of the methyl and carboxyl groups. Acetate produced from D- $\left[3,4-{ }^{14} \mathrm{C}\right]-$ and $\mathrm{D}-[1-$ ${ }^{14} \mathrm{Clglucose}$, on the other hand, would respectively have been labelled in its methyl group or unlabelled (Entner \& Doudoroff, 1952). On these grounds, operation of the Entner-Doudoroff pathway could be excluded.

The small amount $(1 \%$ of total radioactivity) of radioactive acetate produced from D-[3,4${ }^{14} \mathrm{C}$ lglucose (Table 1) was labelled in its carboxyl carbon (Table 4), which is consistent with the fermentation of some glucose by the hexose monophosphate pathway (Fig. $1 b$ ). In view of the 90 -fold higher radioactivity found in lactate (Table 1), it is clear that the hexose monophosphate pathway could only make a minor contribution to the end-products. This is supported by consideration of the fate of the label of $\mathrm{D}-\left[2-{ }^{14} \mathrm{C}\right] \mathrm{glucose}$, which was only recovered in the carboxyl carbon of acetate, and that of $\mathrm{D}-\left[11^{-14} \mathrm{C}\right] \mathrm{glucose}$, where the methyl group of acetate was uniquely labelled (Table 4). Both of these results are predicted for the glycolytic pathway (Fig. 1a).

The labelling patterns of lactate and acetate obtained from $D-\left[2-{ }^{14} \mathrm{C}\right]$ glucose (Table 4) provided additional support for the conclusion that glycolysis was the major pathway of glucose metabolism by $L$. divergens. Lactate and acetate were labelled in the hydroxylated and carboxyl carbons, respectively, as is expected for the glycolytic pathway (Fig. 1a). The specific radioactivities recovered in the carbon atoms after chemical oxidation of lactate and acetate were in all cases about $95 \%$ of the specific radioactivity of the respective labelled fermentation product, suggesting that a single pathway of fermentation was operative.

\section{CONCLUSION}

Lactate is the major product of glucose fermentation by $L$. divergens, since the radioactivities in $\mathrm{CO}_{2}$, acetate and formate never exceeded $10 \%$ of the total radioactivity in the fermentation products (Table 1). L. divergens therefore ferments glucose predominantly by the glycolytic pathway to lactate. The extent to which product dilution had occurred suggests that unknown pathways, using substrates other than glucose, may be operative in $L$. divergens. Their principal products are $\mathrm{CO}_{2}$, acetate and formate, since only $23 \%$ of the total lactate was produced from non-glucose sources (Tables 2 and 3). Endogenous substrates giving rise to these products could include fructose (from sucrose) and/or amino acids. 
The positional distribution of the label of differently labelled glucose precursors in the fermentation products corresponds with the pattern expected for homolactic lactobacilli. It is uncertain to what extent the hexose monophosphate pathway contributed to the fermentation of glucose. At most it constituted about $11 \%$ of the glycolytic pathway, based on the incorporation of radioactivity from $\mathrm{D}-\left[1{ }^{-14} \mathrm{C}\right]$ glucose into $\mathrm{CO}_{2}$ (Table 1 ). The amount of label (Table 1 ) in the carboxyl carbon of acetate (Table 4) from $\mathrm{D}-\left[3,4-{ }^{14} \mathrm{C}\right]$ glucose suggests that this pathway may constitute as little as $1 \%$ of the glycolytic pathway.

Under glucose limitation, L. divergens also produced $\mathrm{CO}_{2}$, acetate and formate by secondary decarboxylation/dissimilation of pyruvate/lactate. It would therefore seem appropriate to reclassify $L$. divergens as belonging to group II of the family Lactobacillaceae recently described by Kandler \& Weiss (1986). This group of lactobacilli had previously been classified as Streptobacterium (Sharpe, 1981). These results emphasize that classification of bacteria should be based on the distribution patterns of labelled C-atoms, rather than on the concentrations of the fermentation products only.

We thank Elna Ellis and Nils Dittmer for technical assistance, and the CSIR and the Department of Agriculture for financial support.

\section{REFERENCES}

Abo-Elnaga, I. G. \& Kandler, O. (1965). Zur Taxonomie der Gattung Lactobacillus Beijerink. 2. Das Subgenus Betabacterium Orla Jensen. Zentralblat für Bakteriologie. Parasitenkunde, Infectionskrankheiten und Hygiene, 2. Abt., 119, 117-129.

Bergmeyer, H. U. \& Möllering, H. (1974). Methods for determination of metabolites:acetate. In Methods of Enzymatic Analysis, 2nd edn, pp. 1520-1528. Edited by H. U. Bergmeyer. New York \& London: Academic Press.

BerNT, E. \& Bergmeyer, H. U. (1974). Methods for determination of metabolites:D-fructose. In Methods of Enzymatic Analysis, 2nd edn, pp. 1304-1307. Edited by H. U. Bergmeyer. New York \& London: Academic Press.

Cluley, H. J. (1962). Suspension scintillation counting of carbon-14 barium carbonate. Analyst 87, 170177.

DAwEs, E. A. (1980). Determination of metabolic pathways. In Quantitative Problems in Biochemistry, 6th edn, pp. 248-267. London \& New York: Longman.

DE BRUYN, I. N., LouW, A. I., VISSER, L. \& HOLZAPFEL, W. H. (1987). Lactobacillus divergens is a homofermentative organism. Systematic and Applied Microbiology 9, 173-175.

ENTNER, N. \& DOUDOROFF, M. (1952). Glucose and gluconic acid oxidation of Pseudomonas saccharophila. Journal of Biological Chemistry 196, 853-862.

GotrschalK, G. (1979). Bacterial fermentation. In Bacterial Metabolism, pp. 218-219. New York: Springer-Veriag.
Guerrant, G. O., Lambert, M. A. \& Moss, C. W. (1982). Analysis of short chain acids from anaerobic bacteria by high performance liquid chromatography. Journal of Clinical Microbiology 16, 355360.

Holzapfel, W. H. \& Gerber, E. S. (1983). Lactobacillus divergens sp. nov., a new heterofermentative Lactobacillus species producing L(+)-lactate. Systematic and Applied Microbiology 4, 522-534.

KANDLER, O. \& WEISS, N. (1986). Genus Lactobacillus. In Bergey's Manual of Systematic Bacteriology, vol. 2, pp. 1209-1234. Edited by P. H. A. Sneath. Baltimore: Williams \& Wilkins.

Noll, F. (1974). Methods for determination of metabolites:L-(+)-lactate. In Methods of Enzymatic Analysis, 2nd edn, pp. 1475-1479. Edited by H. U. Bergmeyer. New York \& London: Academic Press.

Sharpe, M. E. (1981). The Genus Lactobacillus. In The Prokaryotes, pp. 1653-1679. Edited by M. P. Starr, H. Stolp, H. G. Trüper, A. Balows \& H. G. Schlegel. Berlin: Springer-Verlag.

Stams, A. J. M., Hansen, T. A. \& Skyring, G. W. (1985). Utilization of amino acids as energy substrates by two marine Desulfovibrio strains. FEMS Microbiology Ecology 31, 11-15.

Williams, J. F., Rienits, K. G., Schofield, P. J. \& Clark, M. G. (1971). The pentose phosphate pathway in rabbit liver. Biochemical Journal 123, 923-943. 